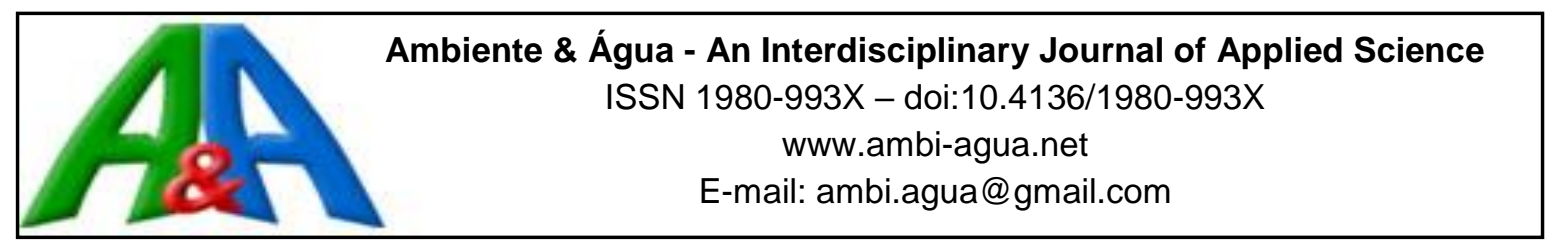

\title{
Expansão urbana da Região Metropolitana de Belém sob a ótica de um sistema de índices de sustentabilidade
}

\author{
doi:10.4136/ambi-agua.1878 \\ Received: 02 Mar. 2016; Accepted: 07 May 2016

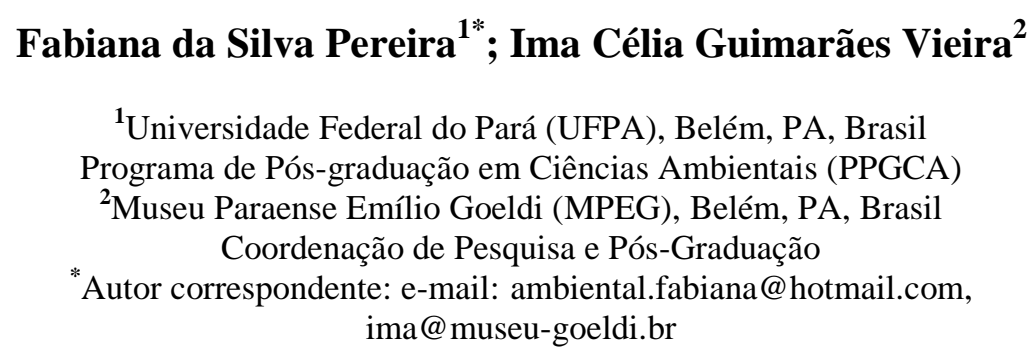

\section{RESUMO}

A região metropolitana de Belém (RMB) concentra 1/3 da população do estado do Pará, Brasil, e sua recente expansão tem causado uma série de problemas sociais e ambientais, que comprometem o acesso à infraestrutura e serviços, e também impactam outros fatores que influenciam a sustentabilidade urbana. Nos últimos anos, várias metodologias de avaliação da sustentabilidade das cidades têm sido propostas, porém os desafios ainda são enormes, no sentido de incorporar uma visão pluridimensional na avaliação da sustentabilidade urbana. No presente trabalho aplicou-se o Sistema de Índices de Sustentabilidade Urbana (SISU) para a RMB, com o objetivo de analisar os níveis de sustentabilidade dos municípios que compõem essa região metropolitana e verificar as limitações e os desafios em aplicar esse método de mensuração na Amazônia. Foram empregados 7 indicadores para o índice de qualidade ambiental (IQA), 4 para o índice de capacidade político institucional (ICP) e o índice de desenvolvimento humano municipal (IDHM). Os resultados obtidos mostram que há pouca variação nos índices IQA e IHDM, sendo que os municípios menos populosos, como Santa Bárbara e Benevides apresentam melhor IQA, e os de maior porte, como Belém e Ananindeua, o melhor IDHM. Entretanto, é em relação ao ICP que esta região metropolitana apresenta a maior desigualdade intermunicipal, refletindo assim, a necessidade do fortalecimento institucional e político dessa região.

Palavras-chave: Amazônia, expansão urbana, indicadores de sustentabilidade.

\section{Urban expansion of the metropolitan region of Belém from the perspective of a sustainability index system}

\begin{abstract}
The metropolitan area of Belém (RMB) contains $1 / 3$ of the population of Pará State, Brazil, and its recent expansion has caused a number of social and environmental problems that undermine access to infrastructure and services and also impact other factors that influence urban sustainability. In recent years, various methodologies for assessing the sustainability of cities have been proposed, but the challenges of incorporating a
\end{abstract}


multidimensional approach in the evaluation of urban sustainability are still enormous. In this work, we applied the Urban Sustainability Index System (SISU) to the RMB in order to analyze the levels of sustainability of the municipalities that constitute this metropolitan area and to verify the limitations and challenges in applying this method of measurement in the Amazon region. Seven indicators were used for the environmental quality index (IQA), and four for the political institutional capacity index (ICP) and the municipal human development index (IDHM). The results show that there is little variation in the IQA and IHDM indices, and the least-populated municipalities such as Santa Barbara and Benevides have better IQAs, while larger-populated municipalities, such as Belém and Ananindeua, have better IDHMs. However, it is in relation to ICP that this metropolitan area has the highest inequality, thus reflecting the need for the institutional and political empowerment of this region.

Keywords: Amazonia, sustainability indicators, urban expansion.

\section{INTRODUÇÃO}

Atualmente há cerca de 25 milhões de habitantes na Amazônia brasileira, a maioria, $72,6 \%$, vivendo em núcleos urbanos (IBGE, 2010). Apesar da taxa de migração ter diminuído nessa última década, o fluxo migratório intra-regional ainda continua, do campo para as cidades, e dos grandes centros urbanos para cidades médias, formando redes urbanas com dinâmicas demográficas, socioeconômicas e espaciais distintas (Sathler et al., 2009).

O modo com que o processo de expansão urbana vem ocorrendo na Amazônia acentua ainda mais os problemas socioeconômicos e ambientais nas cidades. Apesar disso, o que se tem observado é que a questão urbana é negligenciada nos estudos voltados para a região (Becker, 2013), mesmo que esta seja considerada fundamental para a implementação de estratégias do desenvolvimento sustentável (Brasil, 2000).

O Estado nacional com o seu projeto desenvolvimentista para a região amazônica, pós década de 60, aprofundou ainda mais as assimetrias tanto inter quanto intra-regionais. Houve a criação de condições para a expansão de investimentos privados, no entanto, intensificaram se as contradições sociais (Silva, 2015). A partir desse período, com a política de integração nacional, o território amazônico brasileiro sofreu um aumento populacional significativo e foi a partir da percepção dessa nova dinâmica de ocupação que, desde a década de 80, Becker (2005) passa a chamar a Amazônia de "Floresta Urbanizada".

A região metropolitana de Belém (RMB) é a segunda mais populosa da Amazônia. Apesar de corresponder a um território de menos de 1\% do estado do Pará, concentra 1/3 da população estadual (IBGE, 2010) e é a principal expressão de centralidade na Amazônia oriental brasileira. Em seu processo de formação coexistem duas dinâmicas: uma associada à cidade de Belém, um território de 400 anos, como "cidade primaz" da rede amazônica até metade do século $\mathrm{XX}$, e a outra posterior a esse período, em que a região foi incorporada à dinâmica econômica brasileira (Cardoso et al., 2015).

Na cidade de Belém, a intensificação da migração rural-urbana, levou ao adensamento e expansão do seu sítio urbano, que juntamente à falta de políticas públicas introduziram na cidade situações insustentáveis para o contexto amazônico (Cardoso e Ventura Neto, 2013). Há uma grande desigualdade socioespacial na cidade, em que os serviços urbanos estão mais concentrados em determinadas áreas, prioritariamente privilegiadas pela administração pública, que visa atrair investimentos e garantir o sucesso econômico em detrimento das necessidades existentes nas áreas periféricas (Dias, 2008). 
A RMB destaca-se por sua especificidade como espaço urbano, a qual se constitui uma variante do processo de metropolização no Brasil, onde apesar de apresentar-se como centralidade econômica e moderna, integrada a centros dinâmicos regionais, nacionais e internacionais (Cardoso et al., 2015), ainda verifica-se a existência de uma economia tradicional, articulada com a tradição ribeirinha, com a manutenção de alguns padrões rurais (Padoch et al., 2008). Além disso, de modo geral, enfrenta problemas de ordem estrutural, com forte presença de ocupações informais e irregulares, onde se articulam alto nível de desigualdade social e aprofundamento da segregação socioespacial (Fernandes et al., 2015). Isso reflete a necessidade de se traçar estratégias em busca de desenvolvimento pautado na sustentabilidade, de forma a conciliar o equilíbrio ambiental com a qualidade de vida.

Apesar de não haver um consenso sobre o real significado do termo sustentabilidade, há na literatura, diversas tentativas de construção desse conceito (Braga, 2006; Braga et al., 2004; Acserald, 1999). Entretanto, o conceito que talvez melhor represente a sustentabilidade associada ao contexto das cidades é o de Schussel (2004), para o qual uma cidade sustentável teria como base um modelo, um "arquétipo pluridimensional", em que a integração positiva entre o meio ambiente natural, o patrimônio histórico-cultural, a economia e a sociedade possam resultar no máximo bem estar coletivo.

Dessa forma, com o objetivo de promover a sustentabilidade e torná-la mais operacional, desde a década de 90, diversos sistemas de indicadores e ferramentas de avaliação (Guimarães e Feichas, 2009; Braga, 2006, Van Bellen, 2004, Prescott-Allen, 2001), e também modelos de análise (Martins e Cândido, 2015) vêm sendo criados e propostos. Entretanto, ainda imperam muitas incertezas sobre quais sistemas devem ser utilizados na análise da sustentabilidade, se o mesmo conjunto de indicadores pode ser aplicado em diferentes escalas, ou se podem ser aplicados a diferentes contextos, sem comprometer a representatividade das singularidades locais. Embora não exista um sistema ideal, há uma ampla variedade de sistemas de indicadores que podem ser utilizados de acordo com o que se pretende avaliar e em função da disponibilidade dos dados (Marchand e Le Tourneau, 2014).

Neste sentido, o presente trabalho tem como objetivo aplicar um Sistema de Índices de Sustentabilidade Urbana - SISU (Braga, 2006) para a RMB, a fim de verificar os níveis de sustentabilidade dos municípios que a compõem, e também as limitações e os desafios em aplicar esse método de mensuração em uma metrópole amazônica. Escolheu-se essa ferramenta por ter sido desenvolvida para avaliar a sustentabilidade urbana de aglomerados metropolitanos brasileiros, ainda sem aplicação na Amazônia. Além disso, por ser um instrumento composto por índices temáticos, ao invés de um único índice sintético, mostra-se mais sensível para discriminar as diferentes unidades de análise.

\section{MATERIAL E MÉTODOS}

\section{1. Área de estudo}

A região metropolitana de Belém (RMB) foi instituída ainda na década de 70, por meio da Lei Complementar Federal 14/1973. Essa região era composta inicialmente apenas pelos municípios de Belém e Ananindeua. Posteriormente, em 1995, os municípios de Marituba, Benevides e Santa Bárbara do Pará foram incluídos através da Lei Complementar Estadual 27/1995. Em 2010, o município de Santa Isabel do Pará foi integrado à RBM, através da Lei Complementar Estadual 72/2010, e logo em 2011 o município de Castanhal também foi incorporado à região por meio da Lei Complementar Estadual 76/2011 (Figura 1). 
A RMB, segundo os dados censitários do IBGE (2010), tem uma população de 2.275.032 de habitantes, quase um terço da população do estado do Pará, concentrada em uma extensão territorial de $3.565,8 \mathrm{~km}^{2}$, o que representa menos de $1 \%$ da extensão territorial do estado $\left(1.247 .954,32 \mathrm{~km}^{2}\right)$. O PIB da região é de $\mathrm{R} \$ 24.739 .338$ mil para o ano de 2010, um valor baixo quando comparado à cidade de São Paulo, por exemplo, sendo que a capital paraense, Belém, responde por $72,7 \%$ desse total (IBGE, 2010).

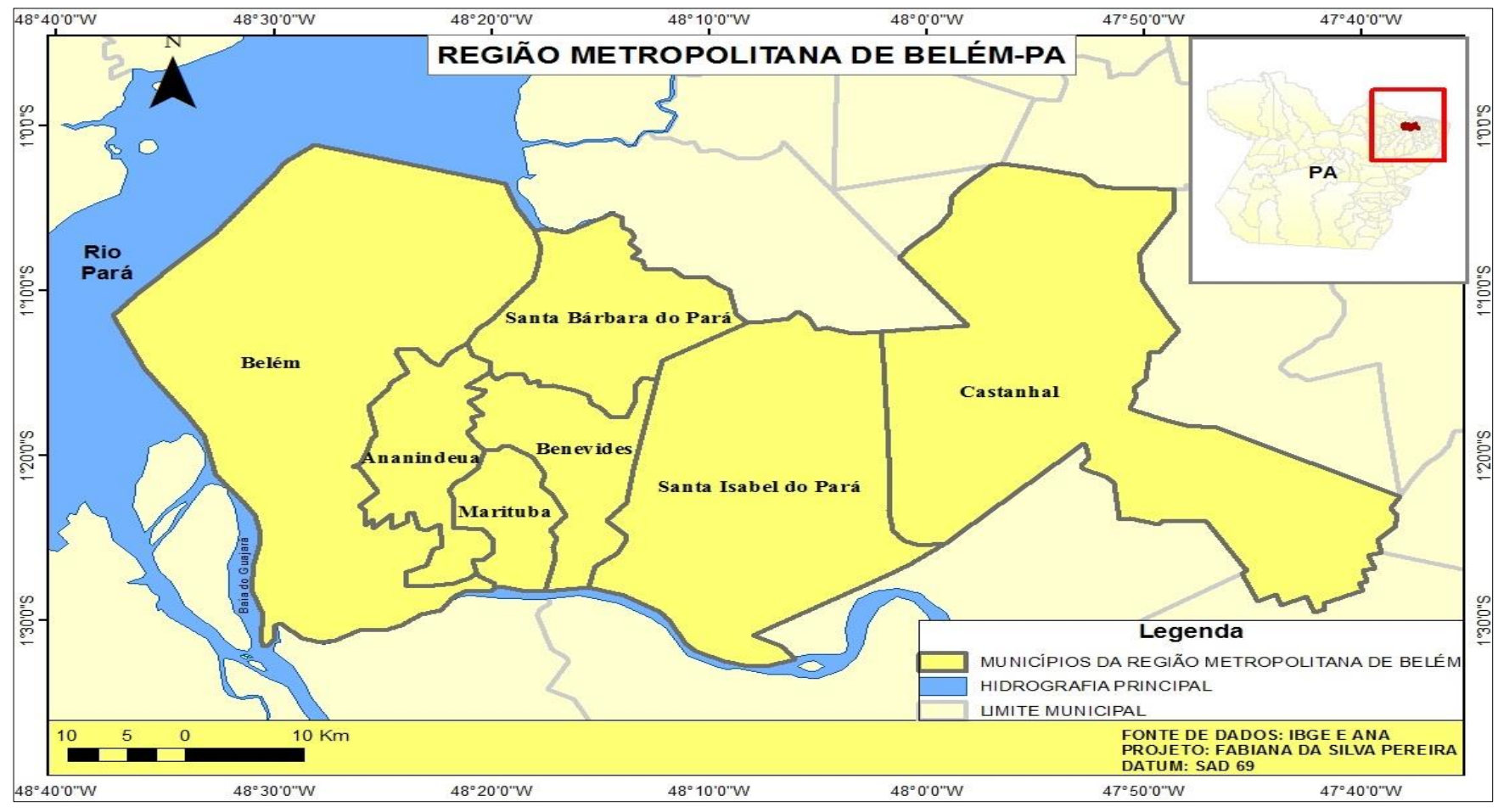

Figura 1. Municípios integrantes da Região Metropolitana de Belém.

Fonte: IBGE e ANA. Elaboração própria.

Belém é também o município da RMB que tem a maior concentração de domicílios, com cerca de 1.393.399 habitantes, e a segunda maior densidade habitacional de 1.315,26 hab. $\mathrm{Km}^{-2}$, atrás apenas do município de Ananindeua, com $2.476,29$ hab. $\mathrm{Km}^{-2}$. Essa população está distribuída em oito distritos administrativos que englobam 71 bairros e 39 ilhas (IBGE, 2010). Além disso, o município de Belém concentra a maior parte dos equipamentos urbanos, e a maior oferta de empregos e serviços (IPEA, 2015). Isso revela a grande disparidade entre o núcleo urbano, que é Belém, e os municípios periféricos.

Dentre as regiões metropolitanas brasileiras, a RMB possui a maior incidência de domicílios em aglomerados subnormais, com 52,5\% do total dos domicílios (IBGE, 2010), ou seja, domicílios em áreas consideradas precárias, em situação de favelização. Essa metrópole, em geral, caracteriza-se pela baixa renda da população, acesso desigual e concentrado na área central do município sede, de infraestrutura, serviços urbanos, acúmulo de capital e emprego (Pinheiro et al., 2013).

\subsection{Aplicação do Sistema de Índices de Sustentabilidade Urbana - SISU}

A escolha dos indicadores e variáveis para construir o SISU tem como base os utilizados por Braga (2006). Neste sistema, os índices ambiental e de capacidade político institucional, foram elaborados e construídos por esta autora. Já o índice de desenvolvimento humano municipal (IDHM) utilizado no SISU é aquele produzido pelo Instituto Brasileiro de 
Geografia e Estatística (IBGE), em parceria com a Fundação João Pinheiro (FJP) e Programa das Nações para o Desenvolvimento (PNUD), para os mais de 5 mil municípios brasileiros.

$\mathrm{O}$ índice de qualidade ambiental (IQA) é composto por oito indicadores (recursos hídricos, cobertura vegetal, serviços sanitários, habitação adequada, pressão industrial, pressão intradomiciliar, pressão por consumo doméstico, pressão automotiva), que medem a qualidade do ambiente em relação aos elementos naturais no momento presente, e também a qualidade do ambiente construído. Já o índice de capacidade político institucional (ICP) é composto por quatro indicadores (autonomia político fiscal, gestão pública municipal, gestão ambiental municipal, e informação e participação política) que visam avaliar a capacidade do sistema político e da sociedade em superar os desafios da sustentabilidade, tanto no presente quanto no futuro.

As variáveis finais que compõem esses indicadores foram escolhidas através de testes estatísticos, a fim de verificar a sua adequação para compor os indicadores, conforme descrito por Braga (2006). Devido à dificuldade de se encontrar essas mesmas variáveis para a RMB, foram utilizadas apenas 20 das 22 variáveis que compõem o SISU. As variáveis que não foram utilizadas são índice de qualidade das águas e peso da imprensa escrita e falada local na imprensa estadual.

$\mathrm{Na}$ Tabela 1 é apresentado o IQA com 7 indicadores subdivididos em 10 variáveis (relação entre a cobertura vegetal remanescente e a área de domínio da cobertura original, acesso à rede pública de fornecimento de água, instalação sanitária adequada, acesso à coleta regular de resíduos sólidos, o inverso da taxa de habitações subnormais, a intensidade energética, média de residentes por cômodos, média de moradores por domicílio, a intensidade no uso energético domiciliar, número de veículos per capta). Alguns desses indicadores são calculados com base em mais de uma variável.

$\mathrm{Na}$ Tabela 2 é apresentado o ICP, com 4 indicadores subdivididos em 10 variáveis (autonomia fiscal, peso eleitoral, porcentagem de funcionários com educação superior, grau de informatização da máquina pública local, existência de instrumentos de gestão urbana, existência e regularidade no funcionamento dos Conselhos Municipais de Desenvolvimento Urbano e de Habitação, existência e a regularidade das reuniões do Conselho de Meio Ambiente, unidades de conservação municipal por 100 mil habitantes, presença de entidades ambientalistas registradas no Cadastro Nacional de Entidades Ambientalistas, participação político eleitoral).

As variáveis selecionadas foram padronizadas pelo método z-score, a fim de torná-las comparáveis, pois permite sua agregação em uma escala numérica única (Braga, 2006). Como algumas variáveis apresentam uma relação inversa com a sustentabilidade, a padronização foi feita pela fórmula inversa. Por último, os indicadores foram padronizados, através do método de máximos e mínimos, em uma escala de 0 a 1 , que correspondem ao valor de pior e melhor indicador, respectivamente, a fim de facilitar a comparação e a comunicação dos resultados. Já os índices temáticos foram obtidos a partir da média simples desses indicadores.

É importante pontuar que os resultados apresentados dentro dessa escala, entre 0 e 1, são uma medida relativa e não absoluta do grau de sustentabilidade, conforme afirma Braga (2006). Ou seja, eles medem o desempenho relativo de cada município em relação ao valor superior e inferior do desempenho do conjunto de municípios analisados. Assim, se um município apresenta a pontuação igual a 1 em algum dos índices, não quer dizer que ele possui o nível máximo, um índice perfeito. Isso quer dizer que o município ainda pode aprimorar o seu desempenho. 
Tabela 1. Indicadores para a construção do índice de qualidade ambiental da região metropolitana de Belém, Pará, ano 2010.

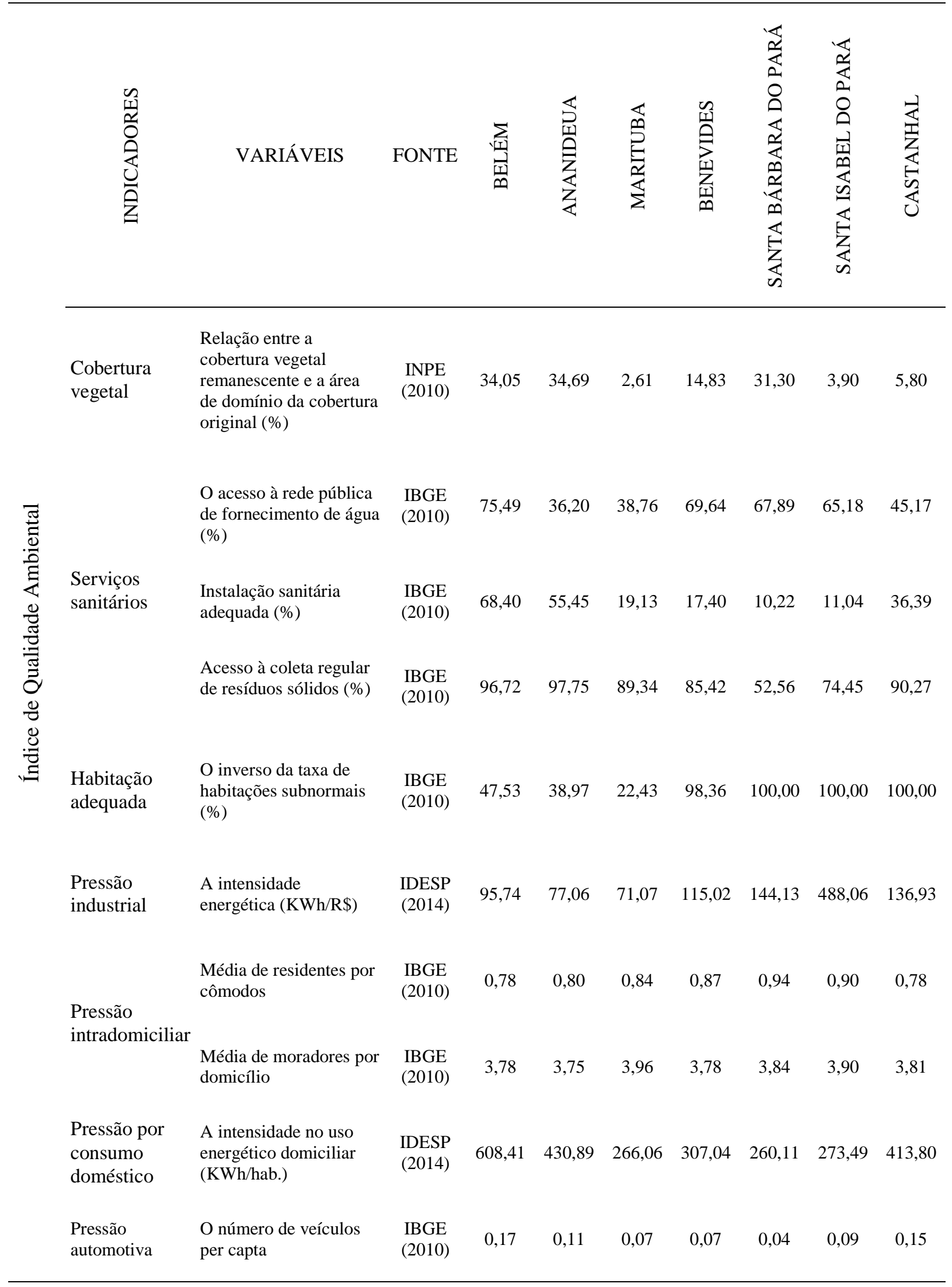


Tabela 2. Indicadores para a construção do índice de capacidade político institucional da região metropolitana de Belém, Pará, ano 2010.

\begin{tabular}{|c|c|c|c|c|c|c|c|c|c|c|}
\hline & 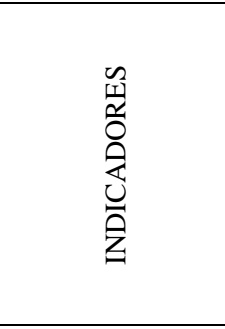 & VARIÁVEIS & FONTE & 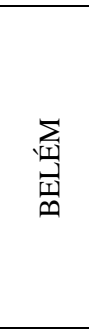 & 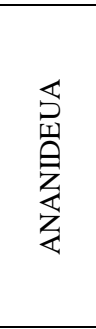 & 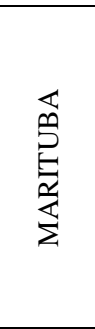 & 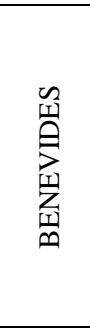 & 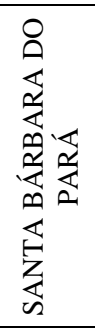 & 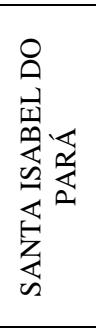 & 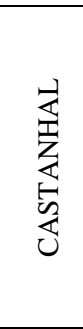 \\
\hline \multirow{6}{*}{\multicolumn{2}{|c|}{ 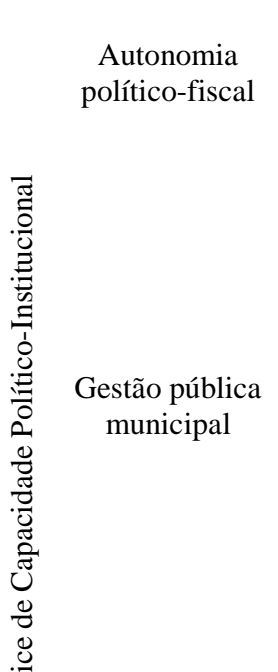 }} & Autonomia fiscal $^{1}$ & IDESP (2014) & 0,84 & 0,42 & 0,21 & 0,14 & 0,04 & 0,13 & 0,23 \\
\hline & & Peso eleitoral $^{2}$ & $\begin{array}{l}\text { IBGE e TSE } \\
\text { (2010) }\end{array}$ & 1,14 & 0,87 & 0,83 & 0,93 & 1,09 & 0,93 & 0,96 \\
\hline & & $\begin{array}{l}\text { Porcentagem de } \\
\text { funcionários com educação } \\
\text { superior }(\%)\end{array}$ & IBGE (2012) & 36,99 & 29,39 & 19,10 & 37,32 & 17,99 & 27,35 & 22,28 \\
\hline & & $\begin{array}{l}\text { Grau de informatização da } \\
\text { máquina pública local }{ }^{3}\end{array}$ & IBGE (2012) & 3,00 & 2,00 & 3,00 & 2,00 & 2,00 & 2,00 & 2,00 \\
\hline & & $\begin{array}{l}\text { Existência de instrumentos } \\
\text { de gestão urbana }\end{array}$ & $\begin{array}{l}\text { IBGE, (2011; } \\
\text { 2012) }\end{array}$ & 3,00 & 3,00 & 3,00 & 2,00 & 2,00 & 3,00 & 3,00 \\
\hline & & $\begin{array}{l}\text { Existência e regularidade no } \\
\text { funcionamento dos } \\
\text { Conselhos Municipais de } \\
\text { Desenvolvimento Urbano e } \\
\text { de Habitação }{ }^{5}\end{array}$ & IBGE (2012) & 2,00 & 2,00 & 0,00 & 1,00 & 0,00 & 2,00 & 1,00 \\
\hline$\vec{\Xi}$ & \multirow{2}{*}{$\begin{array}{l}\text { Gestão ambiental } \\
\text { municipal }\end{array}$} & $\begin{array}{l}\text { Existência e a regularidade } \\
\text { das reuniões do Conselho de } \\
\text { Meio Ambiente }^{6}\end{array}$ & IBGE, 2012 & 2 & 2 & 2 & 0 & 0 & 2 & 0 \\
\hline & & $\begin{array}{l}\text { Unidades de conservação } \\
\text { municipal por } 100 \text { mil } \\
\text { habitantes }\end{array}$ & Brasil (2015a) & 0,00 & 0,42 & 0,00 & 0,00 & 0,00 & 0,00 & 0,00 \\
\hline \multirow{2}{*}{\multicolumn{2}{|c|}{$\begin{array}{l}\text { Informação e } \\
\text { participação } \\
\text { política }\end{array}$}} & $\begin{array}{l}\text { Presença de entidades } \\
\text { ambientalistas registradas no } \\
\text { Cadastro Nacional de } \\
\text { Entidades Ambientalistas }{ }^{7}\end{array}$ & Brasil (2015b) & 1,00 & 1,00 & 0,00 & 0,00 & 0,00 & 1,00 & 0,00 \\
\hline & & $\begin{array}{l}\text { Participação político } \\
\text { eleitoral }(\%)^{8}\end{array}$ & TSE (2012) & 93,38 & 92,82 & 95,11 & 95,47 & 53,88 & 95,02 & 95,30 \\
\hline
\end{tabular}

\footnotetext{
${ }^{1}$ Calculada como a relação entre arrecadação própria (equivale à soma da receita tributária e outras receitas próprias) e os recursos advindos das transferências intergovernamentais.

${ }^{2}$ Calculado como a relação entre o número de eleitores do município sobre o número de eleitores do estado e a população do município sobre a população do estado.

${ }^{3}$ Considerou-se o máximo de respostas positivas para as seguintes questões que compõem esta variável: possui computadores com cesso à internet, todos os computadores têm acesso à internet, a página da prefeitura na internet está ativa.

${ }^{4}$ Considerou-se o máximo de respostas positivas para a existência dos seguintes instrumentos de gestão urbana: existência de plano diretor, existência de lei de zoneamento de uso e ocupação do solo, código de obras.

${ }^{5}$ Considerou-se o máximo de respostas positivas para: existência e regularidade no funcionamento dos Conselhos Municipais de Desenvolvimento Urbano e dos Conselhos Municipais de Habitação.

${ }^{6}$ Considerou-se o máximo de respostas positivas para: existência de Conselho de Meio Ambiente e regularidade das reuniões do Conselho de Meio Ambiente.

${ }^{7}$ A pontuação varia de 0 (não) a 1 (sim).

${ }^{8}$ Proporção de votos válidos nas últimas eleições municipais (Eleições 2012).
} 


\section{RESULTADOS E DISCUSSÃO}

Os resultados obtidos nessa análise foram calculados para o ano base de 2010 . Entretanto, este é apenas um ano de referência, uma vez que se utilizaram para alguns indicadores, valores em anos posteriores. Isso foi necessário devido às limitações existentes, principalmente em relação à atualização temporal de determinados indicadores, dependendo assim de dados censitários, que ocorre a cada decênio.

A Tabela 3 apresenta os índices de qualidade ambiental (IQA), capacidade político institucional (ICP), e o índice de desenvolvimento humano municipal (IDHM), resultado da aplicação do SISU para os 7 municípios que compõem a região metropolitana de Belém.

Tabela 3. Índices temáticos por município da RMB, para o ano de referência 2010.

\begin{tabular}{lccc}
\hline MUNICÍPIOS & IQA & ICP & IDHM \\
\hline Belém & 0,596 & 0,868 & 0,746 \\
Ananideua & 0,628 & 0,732 & 0,718 \\
Marituba & 0,502 & 0,405 & 0,676 \\
Benevides & 0,756 & 0,309 & 0,665 \\
Santa Bárbara do Pará & 0,787 & 0,107 & 0,627 \\
Santa Isabel do Pará & 0,510 & 0,585 & 0,659 \\
Castanhal & 0,563 & 0,317 & 0,673 \\
\hline
\end{tabular}

Nota-se uma enorme variação nos ICPs dos municípios que compõem a RMB, sendo que Belém apresenta os maiores ICP e IDHM. A maior capacidade políticoinstitucional de Belém tem destaque uma vez que possui maior desenvolvimento, concentra a maior parte dos equipamentos urbanos, maior robustez institucional, capacidade de centralização do poder e polarização, características essas, próprias de capitais dos estados brasileiros. Braga (2006) ao aplicar esse sistema de índices na região metropolitana de São Paulo e Belo Horizonte, também encontrou o mesmo padrão, em que as capitais apresentaram os melhores resultados para o ICP.

Observa-se também que os municípios que apresentaram melhor ICP, apresentaram um IQA insatisfatório (Tabela 3). Esse mesmo resultado foi encontrado por Braga (2006), em que as capitais São Paulo e Belo Horizonte apresentaram indicadores de capacidade político institucional superiores às demais cidades de suas regiões metropolitanas e o IQA baixo. Entretanto, segundo a autora, esperava-se que com um maior fortalecimento institucional, maior fosse a capacidade dos municípios em traçar estratégias e adotar medidas para promover a sustentabilidade, de modo que refletisse nesse índice.

A capital Belém apesar de não apresentar a pior situação em relação ao IQA, obteve um índice pouco satisfatório. Os indicadores que apresentaram os piores desempenhos foram pressão automotiva, pressão por consumo doméstico, e habitação adequada (Figura 2). Essa cidade apresenta um fluxo de veículos cada vez mais intenso, constituindo-se assim um dos maiores desafios que a metrópole enfrenta, que é a questão da mobilidade urbana. $\mathrm{O}$ transporte público é insuficiente e de baixa qualidade, e o tempo de espera nos engarrafamentos tornam a situação ainda pior. Além disso, esse cenário pode comprometer a qualidade do ar e também a qualidade de vida dos cidadãos. Outro grande desafio que a cidade enfrenta é em relação aos assentamentos precários, reflexo de um processo de 
ocupação desordenada e sem planejamento urbano. Essas habitações irregulares e inadequadas comprometem a segurança ambiental, uma vez que, em sua maioria, são carentes de serviços públicos essenciais (IPEA, 2015), podendo em alguns casos proporcionar um risco de morbidade e mortalidade. Essas mudanças na ocupação urbana, em algumas áreas de expansão da cidade de Belém, comprometem a acessibilidade devido à falta de eixos de conexão suficientes, ou seja, devido à falta de uma rede viária contínua, comprometendo os fluxos, diminuindo assim a integração e a cobertura dos serviços de transporte público (Lima et al., 2014).

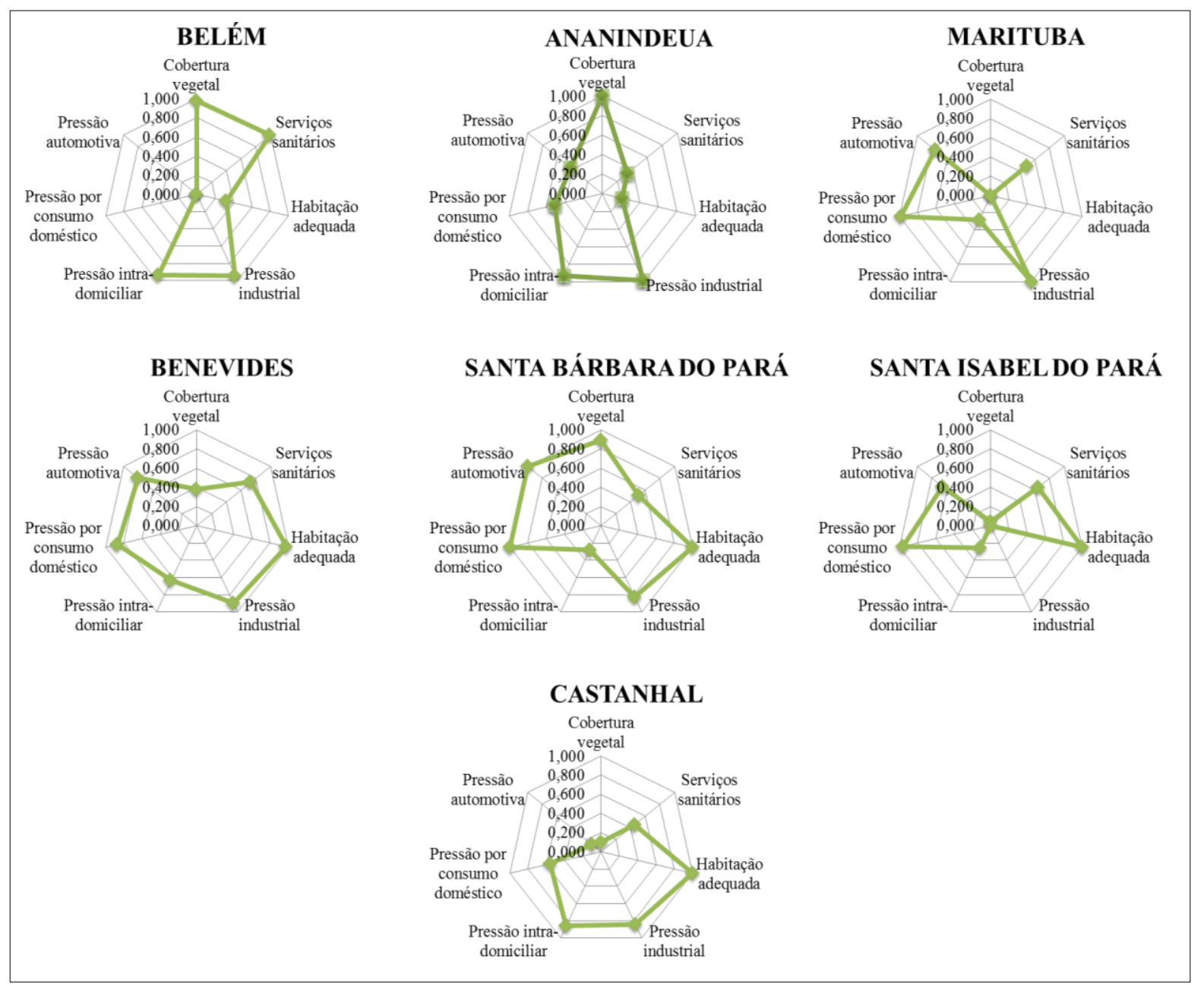

Figura 2. Radar do índice de qualidade ambiental (IQA) dos sete municípios que compõem a região metropolitana de Belém.

Um fator importante é que apesar de Belém apresentar um bom desempenho do indicador de cobertura vegetal (Figura 2), vale ressaltar que o município é composto por uma parte continental e insular. A parte insular ocupa grande parte do território, e a proporção do desmatamento é bem menor (30,3\%) quando comparada à parte continental $(87,5 \%)$ (Ferreira et al., 2012). Assim, se fosse levado em consideração apenas a parte continental, onde reside a maior parte da população, este indicador de cobertura vegetal apresentaria um desempenho bem crítico.

$\mathrm{Na}$ RMB, o IQA para os municípios de pequeno porte populacional tende a ser ligeiramente superior (Tabela 3). O município de Santa Bárbara do Pará é o que apresenta o maior IQA, seguido pelo município de Benevides. Esses municípios são os municípios de menor porte da RMB, com 17.141 e 51.65 mil habitantes, respectivamente. Entretanto, 
apresentam os menores ICP. Os indicadores que apresentam o melhor desempenho no IQA do município de Santa Bárbara do Pará foram habitação adequada, pressão por consumo doméstico, pressão automotiva, cobertura vegetal e pressão industrial, já do município de Benevides destacam-se habitação adequada, pressão industrial, pressão por consumo doméstico e pressão automotiva (Figura 2).

Diferentemente do IQA, o IDHM apresenta-se ligeiramente melhor nos municípios de maior porte populacional, como é o caso de Belém e Ananindeua, com 1.393.399 e 471.980 habitantes, respectivamente. Além disso, esses municípios apresentam os maiores PIBs, e juntos concentram $87,6 \%$ do produto interno bruto da RMB (IBGE, 2010). Esse índice é calculado a partir de três dimensões: educação, longevidade e renda. Em ambos os municípios, Belém e Ananindeua, é em relação ao IDHM-longevidade, que utiliza dados de esperança de vida ao nascer, que estes apresentam os melhores resultados (FAPESPA, 2015). O IDHM acaba recebendo muitas críticas por não considerar outras características sociais, culturais e políticas importantes, e que influenciam na qualidade de vida humana.

Os municípios da RMB apresentaram as piores performances quanto ao índice de capacidade político institucional. É neste índice também que se observam as maiores diferenças intermunicipais. Esses resultados presumem que os níveis de governança metropolitana são baixos, reflexo de um sistema institucional deficiente. Não ocorre urbanização homogênea do território, o que contribui para que o predomínio das políticas urbanas nos municípios seja voltado para a resolução dos seus problemas em menor escala, sem um sistema político institucional integrado capaz de enfrentar os desafios da sustentabilidade.

O melhor desempenho quanto a este índice foi observado para a cidade de Belém e o pior ocorreu no município de Santa Bárbara, os municípios de maior e menor porte populacional, respectivamente. Os indicadores da cidade de Belém que apresentaram melhores resultados foram autonomia político-fiscal, gestão pública municipal, e informação e participação política (Figura 3). Esses resultados podem estar relacionados com o maior volume de recursos que esse município possui, pois concentra a maior quantidade de equipamentos públicos, de empresas e atividades, e população, características essas que corroboram para uma atuação mais efetiva do poder público na gestão de políticas urbanas e também sociais (IPEA, 2015).

Já o município de Santa Bárbara apresentou os piores valores para os indicadores de informação e participação política, gestão ambiental municipal e gestão pública municipal (Figura 3). Esses dados mostram que esse município apresenta resultados preocupantes quanto à eficiência da máquina pública na gestão pública municipal e gestão ambiental, quanto à existência de mecanismos de gestão urbana, e também em relação ao grau de interesse e envolvimento da população no governo local e em questões relacionadas ao meio ambiente. Entretanto, como já exposto, apesar do município apresentar desempenho crítico em relação à gestão ambiental, esse foi o município que apresentou o melhor IQA.

É importante ressaltar que não existe uma instância de articulação política ou institucional efetiva dos municípios da RM de Belém na abordagem da questão metropolitana e nem há integração de políticas públicas locais entre eles, conforme aponta o IPEA (2015). Historicamente, a RMB é uma sucessão de divisões territoriais e de criação de novos espaços periféricos e pobres (IPEA, 2015) e assim, cada município-membro, na perspectiva da administração pública local, prioriza as intervenções consideradas prioritárias para sua respectiva realidade, por meio de obras de pavimentação, saneamento básico e abastecimento de água. 


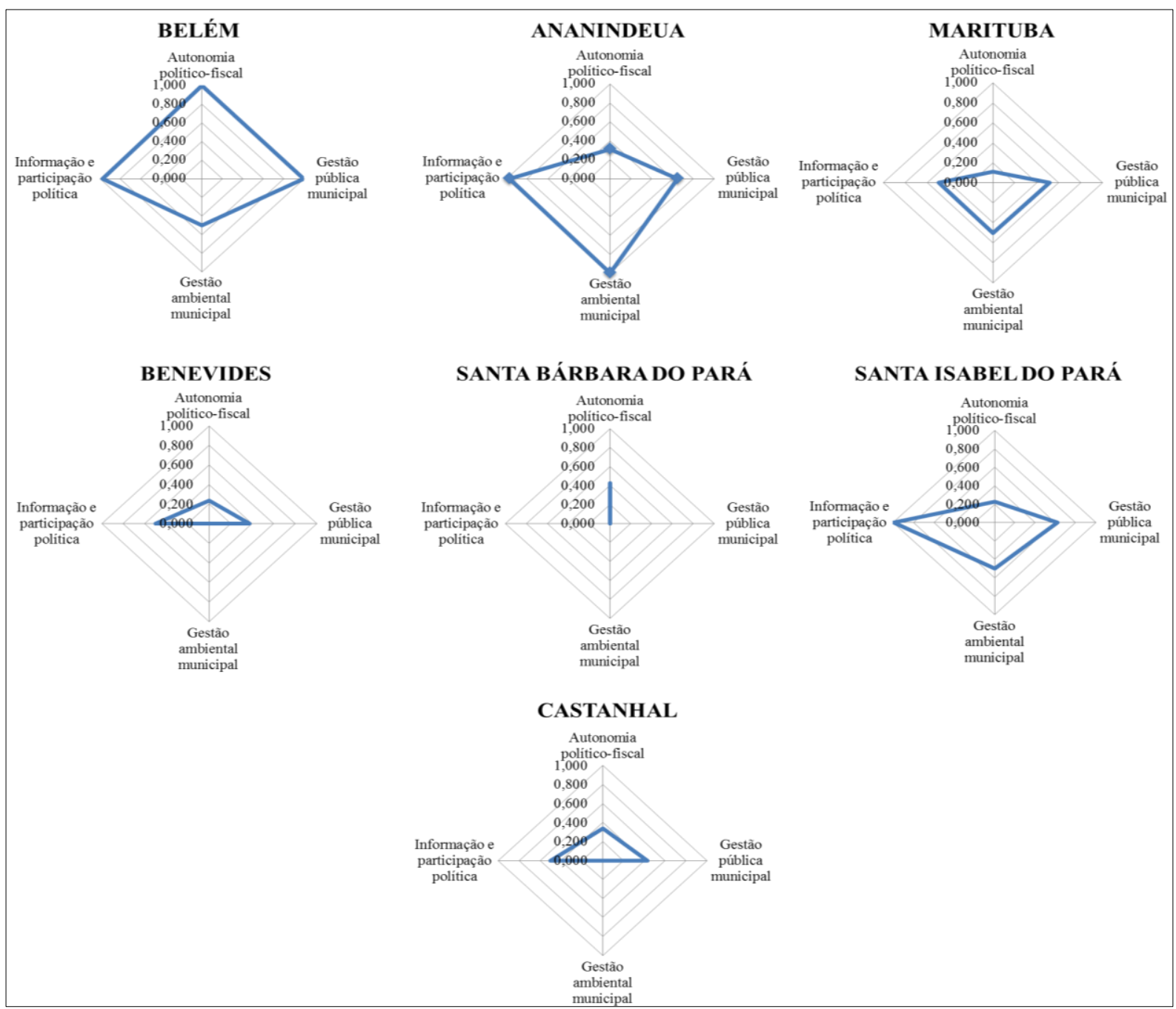

Figura 3. Radar do índice de capacidade político institucional dos sete municípios que compõem a região metropolitana de Belém.

\section{CONCLUSÃO}

Os resultados demonstraram que índices temáticos aplicados à RBM têm aplicação para uma metrópole amazônica, podendo assim ser utilizado como instrumento de monitoramento e fornecem informações necessárias para direcionar esforços e políticas públicas. Entretanto, há alguns desafios, devido, principalmente, a falta de dados, o que acabou impedindo a utilização de algumas variáveis. Chama-se atenção especial para a falta de dados de qualidade ambiental, evidenciando assim a necessidade e urgência de investimentos no monitoramento de variáveis ambientais e na construção de séries temporais de dados. Nesse sistema não foram incorporados indicadores importantes para a qualidade do ambiente natural, tais como qualidade do ar, do solo e da água, devido justamente à carência dessas informações.

Além disso, a escolha por utilizar o IDHM para compor o sistema de índices, não é satisfatória, pois é pouco sensível. Os resultados desse índice não refletem as desigualdades intramunicipais existentes, em toda sua dimensão. Dessa forma, não foi possível avaliar as desigualdades existentes em temas importantes como saúde, educação e renda.

Os municípios que apresentam conurbação, Belém e Ananindeua, juntos concentram a maior parte da população e das atividades econômicas. Essas características podem se configurar um desafio ainda maior à gestão urbana e à construção da sustentabilidade, pois podem significar uma maior pressão sobre os recursos naturais, o que pode comprometer a 
qualidade ambiental e consequentemente a qualidade de vida da população. Entretanto, essas mesmas características podem representar um ambiente favorável, já que são os municípios que apresentaram as melhores condições político-institucionais e sociais, o que pode facilitar a implementação de estratégias chaves para o desenvolvimento sustentável.

Em geral, percebe-se que o maior desafio para a RMB é em relação à dimensão político-institucional. A maioria dos municípios apresenta fragilidade institucional, constituindo-se assim uma barreira para o alcance da sustentabilidade. Portanto, é necessário a avaliação e monitoramento das variáveis que compõe essa dimensão, tanto territorial quanto temporal.

\section{AGRADECIMENTOS}

Este artigo é parte de uma dissertação de Mestrado Interinstitucional em Ciências Ambientais do Programa de Pós Graduação em Ciências Ambientais do convênio entre a Universidade Federal do Pará, Museu Paraense Emílio Goeldi e Embrapa Amazônia Oriental. Os autores agradecem o apoio financeiro do INCT/ Biodiversidade e Uso da Terra na Amazônia, à Fundação Coordenação de Aperfeiçoamento de Pessoal de Nível Superior Capes pela concessão da bolsa de estudo (Mestrado) à primeira autora; ao CNPq pela bolsa de produtividade à segunda autora, Processo CNPq N. 306368/2013-7.

\section{REFERENCIAS}

ACSELRAD, H. Discursos da sustentabilidade urbana. Revista Brasileira de Estudos Urbanos e Regionais, n. 1, 1999.

BECKER, B. K. Geopolítica da Amazônia. Estudos Avançados, v. 19, n. 53, 2005. http://dx.doi.org/10.1590/S0103-40142005000100005

BECKER, B. K. A urbe amazônida: a floresta e a cidade. Rio de Janeiro: Garamond, 2013. $88 \mathrm{p}$.

BRAGA, T. Sustentabilidade e condições de vida em áreas urbanas: medidas e determinantes nas Regiões Metropolitanas de São Paulo e Belo Horizonte. Revista Latinoamericana de Estudios Urbano Regionales (EURE), v. 32, n. 96, p. 47-71, 2006.

BRAGA, T.; FREITAS, A. P. G.; DUARTE, G. S.; CAREPA-SOUSA, J. Índices de sustentabilidade municipal: o desafio de mensurar. Nova Economia, Belo Horizonte, v. 14, n. 3, p. 11-34, 2004.

BRASIL. Ministério do Meio Ambiente - MMA. Cadastro Nacional de Entidades Ambientalistas - CNAE. Disponível em: http://www.mma.gov.br/port/conama/ cnea/cneaenti1.cfm. Acesso em: 18 de out. 2015b.

BRASIL. Ministério do Meio Ambiente - MMA. Cidades sustentáveis: subsídios à elaboração da agenda 21 brasileira. Brasília, 2000. 155p.

BRASIL. Ministério do Meio Ambiente - MMA. Consultar - Unidades de Conservação. Disponível em: http://sistemas.mma.gov.br/portalcnuc/rel/index.php?fuseaction=por tal.consultarFicha. Acesso em: 18 de out. 2015a. 
CARDOSO, A.; FERNANDEZ, D.; BASTOS, A; SOUSA, C. A Metrópole Belém e sua centralidade na Amazônia Oriental Brasileira. Revista Latinoamericana de Estudios Urbano Regionales (EURE), v. 41, n. 124, p. 201-223, 2015. http://dx.doi.org/10.4067/S0250-71612015000400010

CARDOSO, A. C. D.; VENTURA NETO, R. S. A evolução urbana de Belém: trajetória de ambiguidades e conflitos socioambientais. Cadernos Metropolitano, v. 15, n. 29, p. $55-75,2013$.

DIAS, J. A. M. Conflitos ambientais urbanos em Belém/Pa. In: ENCONTRO NACIONAL DOS ANPPAS, 4., 2008, Brasília. Anais... Brasília: ANPPAS, 2008.

FUNDAÇÃO AMAZÔNIA DE AMPARO A ESTUDOS E PESQUISAS DO PARÁFAPESPA. Diretoria de Estatística e de Tecnologia e Gestão da Informação. Estatísticas municipais paraenses. Belém, 2015.

FERNANDES, D. A.; SOUSA, C. N.; RODRIGUES, D. L. A metrópole Belém na transição econômica: estrutura produtiva e mercado de trabalho. In: CARDOSO, A. C. D.; LIMA, J. J. F. (Orgs.). Belém: transformações na ordem urbana. Rio de Janeiro: Letra Capital: Observatório das Metrópoles, 2015. p.89-120.

FERREIRA, L. V.; PAROLIN, P.; MUÑOZ, S. H.; CHAVES, P. P. O efeito da fragmentação e isolamento florestal das áreas verdes da região metropolitana de Belém. Pesquisas. Botânica, n. 63, p. 357-367, 2012.

GUIMARÃES, R. P.; FEICHAS, S. A. Q. Desafios na construção de indicadores de sustentabilidade. Ambiente \& Sociedade, v. 12, n. 2, p. 307-323, 2009. http://dx.doi.org/10.1590/S1414-753X2009000200007

InSTITUTO BRASILEIRO DE GEOGRAFIA E ESTAtísTICA - IBGE. Censo 2010. 2010. Disponível em: http://cidades.ibge.gov.br/xtras/perfil.php?codmun=150140. Acesso em: 15 out. 2015.

INSTITUTO BRASILEIRO DE GEOGRAFIA E ESTATÍSTICA - IBGE. Pesquisa de Informações Básicas Municipais - Gestão Pública. 2012. Disponível em: http://munic.ibge.gov.br/index.php? $\mathrm{ff}=15 \&$ nome $=\& \mathrm{x}=69 \& \mathrm{y}=14 \&$ periodo $=2011$. Acesso em: 16 out. 2015.

INSTITUTO DE DESENVOLVIMENTO ECONÔMICO, SOCIAL E AMBIENTAL DO PARÁ - IDESP. Estatísticas Municipais 2014. 2014. Disponível em: http://web.fapespa.pa. gov.br/equilibrium/produto/estatisticamunicipal/98 . Acesso em: 10 out. 2015.

INSTITUTO DE PESQUISA ECONÔMICA APLICADA - IPEA. Governança metropolitana no Brasil: região metropolitana de Belém. Rio de Janeiro, 2015. 82 p.

INSTITUTO NACIONAL DE PESQUISAS ESPACIAIS - INPE. Banco de dados do projeto Programa de Monitoramento da Amazônia por Satélite- PRODES. 2010. Disponível em: http://www.dpi.inpe.br/prodesdigital /prodes.php. Acesso em: 16 out. 2015. 
LIMA, J. J. F.; VENTURA NETO, R. S.; CRUZ, C. C. S. Modificações recentes na configuração da periferia de Belém do Pará e suas consequências para mobilidade urbana. In: ENCONTRO DA ASSOCIAÇÃO NACIONAL DE PESQUISA E PÓSGRADUAÇÃO EM ARQUITETURA E URBANISMO, 3., 2014, São Paulo. Anais... São Paulo: Associação Nacional de Pesquisa e Pós-graduação em Arquitetura e Urbanismo; PUC Mackenzie, 2014. v. 1. p. 1-20.

MARCHAND, G.; LE TOURNEAU, F. M. O desafio de medir a sustentabilidade na Amazônia: os principais indicadores e a sua aplicabilidade ao contexto amazônico. In: VIEIRA, I. C. G. (Org.). Ambiente e sociedade na Amazônia: uma abordagem interdisciplinar. Rio de Janeiro: Garamond, 2014. p. 155-220.

MARTINS, M. F.; CÂNDIDO, G. A. Modelo de avaliação do nível de sustentabilidade urbana: proposta para as cidades brasileiras. URBE. Revista Brasileira de Gestão Urbana, v. $7, \quad$ n. 3 , p. 397-410, 2015. http://dx.doi.org/10.1590/21753369.007.003.AO09

PADOCH, C.; E. BRONDIZIO; COSTA, S.; PINEDO-VASQUEZ, M.; SEAR, R. R.; SIQUEIRA, A. Urban forest and rural cities: multi-sited households, consumption patterns, and forest resources in Amazonia. Ecology and Society, v. 13, n. 2, 2008.

PINHEIRO, A. C. L.; RODRIGUES, R. M.; PONTE, J. P. X.; MONTE, L. F. O.; SABINO, T. A. G. Desafios da governança metropolitana na região metropolitana de Belém: alguns apontamentos. In: COSTA, M. A.; TSUKUMO, I. T. L. (Orgs.). 40 anos de regiões metropolitanas no Brasil. Brasília: IPEA, 2013. p. 47-67

PRESCOTT-ALLEN, R. The wellbeing of nations: a country-by-country index of quality of life and the environment. Washington DC,: Island Press, 2001. 367p.

SATHLER, D.; MONTE-MÓR, R. L.; CARVALHO, J. A. M. As redes para além dos rios: urbanização e desequilíbrios na Amazônia brasileira. Nova Economia, v.19, n.1, p.1139, 2009. http://dx.doi.org/10.1590/S0103-63512009000100002

SCHUSSEL, Z. G. L. O desenvolvimento urbano sustentável - uma utopia possível? Desenvolvimento e Meio Ambiente., n. 9, p. 57-67, 2004. http://dx.doi.org/10.5380/dma.v9i0.3081

SILVA, A. T. da. Amazônia na agenda ambiental global. Belém: NUMA/UFPA, 2015. $265 p$.

TRIBUNAL SUPERIOR ELEITORAL - TSE (Brasil). Estatísticas e resultados das eleições 2012: quadro de votação. 2012. Disponível em: http://www.tse.jus.br/eleicoes/estatisticas/estatisticas- eleicoes-2012. Acesso em: 17 out. 2015.

VAN BELLEN, H. M. Desenvolvimento sustentável: uma descrição das principais ferramentas de avaliação. Ambiente \& Sociedade, v. 7, n. 1, 2004. http://dx.doi.org/10.1590/S1414-753X2004000100005 